When the diathermy is applied to the thorax or neck of an insulated patient the shortest electrical path is through the anaesthetic tubing and machine or the anaesthetist, who usually has bare hands and conducting boots. When patients are intubated, the endotracheal tube is non-conducting when dry, and electrical contact is first made with the metal connector, which can easily make contact with the skin of the face but is often bound with adhesive tape; nevertheless, we are sure that sooner or later an electrical burn of the lips will be reported.

It is an impression, although we do not have statistical proof, that more patients complain of unexpected sore throats (following easy intubation and short duration) who have had diathermy than those that have not. Could this be due to an electrical contact on a wet endotracheal tube ? A further observation is that surgeons need the diathermy turned up higher in patients who are insulated from the table, and are relying on the return through the body to the leg plate.

It is our personal opinion that no insulating material should separate the patient from the antistatic mattress on an operating table or, alternatively, that anaesthetic machines, anaesthetists, and any other agent making direct contact with the patient should also be insulated from earth.-We are, etc.,

$$
\begin{aligned}
& \text { ARnold A. Warltier. } \\
& \text { BetTy R. WARLTIER. } \\
& \text { St. Stephen's Hospital, } \\
& \text { London S.W.10. }
\end{aligned}
$$

\section{Splenic Rupture in Infectious Mononucleosis}

SIR,-In view of the correspondence on the topic of ruptured spleen in infectious mononucleosis (30 October, p. 1066), I thought it worth reporting the following case.

A student aged 16 was admitted as an emergency a few weeks ago, having been kicked over the left lower ribs while playing rugby football. He was admitted to the Plymouth General Hospital early in the evening, when a diagnosis of ruptured spleen was made and a laparotomy performed. This confirmed the diagnosis of haemoperitoneum due to a ruptured spleen, and splenectomy was undertaken. The spleen weighed $312 \mathrm{~g}$. The patient made a first-class recovery.

A routine post-operative blood count unexpectedly revealed typical changes of infectious mononucleosis, and this finding was confirmed on a subsequent examination. In addition, the Paul-Bunnell test was positive at a titre of 1 in 224 .

I think it is interesting to observe that this young man's injury was not particularly severe, and it seems likely that the abnormal state of the spleen was partly responsible for its rupturing. It is also interesting that he had no previous complaints regarding the prodromal symptoms of his infectious mononucleosis. However, when he was directly questioned he did say that he had been feeling less well than usual in the previous few days; although this could not have been very severe if he felt well enough to engage in a game of rugby football for his college. Subsequent examination did confirm the presence of enlarged tender cervical lymph nodes.-I am, etc., Plymouth General Hospital,
Devonport.

William J. Gall.

\section{Hydrazine Poisoning}

SIR,-A few weeks ago, when medical officer in a West African hospital which has no biochemistry laboratory, I had to deal with the problem of a young Englishman who had drunk hydrazine instead of water when working in a ship's engine-room. Hydrazine has the formula $\mathrm{N}_{2} \mathrm{H}_{4}$ and is used, greatly diluted, to prevent corrosion in ships' boilers by sea-water.

The patient, a sailor, had been drinking beer during the afternoon and early evening. However, it was considered that he was fit for duty, and he was apparently quite competent until the accident. The quantity of hydrazine drunk was not known, but it was between a mouthful and a cupful.

Immediately after drınking this alkaline, concentrated solution he vomited and came up on deck to report to the officer at 11.30 p.m. He was given raw egg and milk, which he vomited, and within a few minutes he collapsed and became unconscious.

On admission at midnight he was flushed, afebrile, unconscious, continent, and vomiting. The pupils were dilated, central, and reacted to light. There was no chemical burn of the lips or mouth. He was able to swallow. In other respects the central nervous system and respiratory and cardiovascular systems were normal on clinical examination.

The stomach was washed out with warm water, which was partially siphoned and partially vomited back. $\mathrm{He}$ was given intramuscular chloroquine sulphate, malaria being endemic in the region; cyanocobalamin, as it was thought that the chemical may have had a cyanide-like effect ; and ascorbic acid; these were given intravenously with dextrose, dextrose-saline, and Hartmann's solution, in all 3 litres within 16 hours. He passed via catheter a total of $600 \mathrm{ml}$. of urine which was alkaline; the state of his bladder on admission was not determined, but could not be palpated through the well-covered abdominal muscles.

Twelve hours after the ingestion of the hydrazine his condition was unchanged, except that vomiting had ceased, his pupils were smaller and diverging to the right, and he had two episodes of violence, requiring restraint by four strong African nurses. Sixteen hours after the accident he was more flaccid, and again violent, so it was decided to send him to the U.K. by air. He was flown out 33 hours after the accident. However, on reaching France the pilot of the aircraft refused to accept further responsibility, as the patient's respirations were irregular and shallow, although apparently there was no cyanosis.

At about midnight, 48 hours after the accident, the patient was admitted to Professor Michel Gaultier's Unit, at the Fernand Widal Hospital, Paris, under the care of Dr. J. P. Frejaville, who kindly sent back a detailed report of the events thereafter.

The patient was intubated under thiopentonesuccinylcholine anaesthesia and given mechanically assisted respiration for the next ten hours. $\mathrm{He}$ was also given $10 \%$ dextrose and vitamin $\mathrm{B}_{0}$. His condition on admission was described as comatose and convulsive. He continued to improve hour by hour, but he passed only $200 \mathrm{ml}$. urine, which condition responded to intravenous chlorothiazide, giving a diuresis of $2,500 \mathrm{ml}$.

However, there was concern about his neurological state. His psyche, memory, voluntary movements, and higher functions were normal, but he had ataxia, even with the eyes open, a lateral nystagmus to the right, and loss of vibration sense. He was unable to write, but could draw ; there was paraesthesia of all four limbs a the extremities; he was unable to reproduce with one hand movements imposed upon the other. There was severe hypoaesthesia of the hands, especially of the right hand, in the distribution of the radial nerve. The E.E.G. tracing and results of ophthalmological examination were within normal limits. The tendon reflexes were normal.
Fortunately the ataxia was improving to the extent that it was anticipated that the young man would be able to travel by air to England, unescorted, about two weeks after he had left Africa.

His final condition is not yet known, but this case is reported in some detail as hydrazine is widely used and its toxic manifestations not widely known.-I am, etc.,

General Hospital,

Jersey, Channel Islands.

F. JAMES Reid.

\section{Problems of Orthopaedic Appointments}

SIR,-I am sure that no one who read Mr. W. J. W. Sharrard's forceful and disturbing letter (16 October, p. 940) could fail to sympathize with him on every point, but I cannot see the value of Mr. N. J. Blockey's contribution (30 October, p. 1060).

His figure of 18 new cases seen by each consultant per week is hardly calculated to arouse the sympathy of general practitioners like myself, while the naivety of his proposals to lighten this somewhat less than gargantuan labour compels me to submit the following assertions for his consideration:

(1) The main causes for reference to orthopaedic clinics are $(a)$ because they provide virtually the only access to physiotherapy, and (b) to obtain appliances which only a specialist may prescribe. (Many a haemarthrosis is aspirated by a general practitioner who is not considered competent to prescribe Tubigrip.)

(2) Given the condition that the cost to a patient to see either a general practitioner or a specialist is the same, in this case nothing, then, other things being equal, he will tend to see a specialist.

(3) Other things are not equal, and the cult of super-specialization probably owes as much to the activities of the British Orthopaedic Association in the 1930s as to anything.

Finally, Sir, in passing, I was intrigued to learn that the specialty of orthopaedics in the Western Infirmary began in 1946. Was then Macewen's work on bone and bonegrafting but another figment of Celtic mythology ?-I am, etc.,

Oldham, Lancs. Kenneth S. Mackenzie.

\section{Oral Contraceptives and Alopecia Areata}

SIR,-I was very interested to read (6 November, p. 1124) of Dr. Grant Peterkin's case of regrowth of hair in a patch of alopecia in a patient taking an oral contraceptive drug. This parallels a similar case in my own experience.

The patient, aged 32 , had suffered from alopecia from the age of 3 or 4 after an attack of asthma. On the first occasion she lost almost her entire head of hair and it took three years to recover. From then onwards she suffered from patchy alopecia, which always recovered slowly. Treatment with massage, sun rays, stimulating lotions, intralesional and systemic steroids was largely without benefit. The patient noted, however, that the alopecia always cleared up during each of her three pregnancies and relapse occurred three to four months after delivery. After her third pregnancy she presented with patches behind her left ear, at the nape and the right parieto-occipital region. As she did not wish to increase her family further 